${ }^{24}$ Clarke, R. O., Proc. Cent. Assembly Inst. Actuaries, 2, 12 (1950). ${ }^{25}$ Jones, H. B., "Advanc. Biol. Med. Phys.”, 4, 281 (1956).

${ }^{28}$ Curtis, H. J., and Healey, R., in "Advances in Radiobiology", edit. by de Hevesy, G. C., Forssherg, A. G., and Abbatt, J. D. ('oliver and Boyd, Edinburgh, 1957).

${ }^{27}$ Curtis, H. J., and Gebhard, K. L., in "Peaceful Uses of Atomic Fnergy", 22 (United Nations, Geneva, 1958).

${ }^{88}$ Shannon, C. E., and Weaver, W., "The Mathematical Theory of Communication" (Univ. Illinois Press, Urbana, 1949).

${ }^{20}$ Lorenz, E., Jacobson, L. O., Heston, W. E., Shimkin, M., Eschenbrenner, A. B., Deringer, Margaret K., Doniger, Jane, and Schweisthal, $R$." in "Biological Effects of External $X$ and Gamma Radiation", edit. by Zirkle, R. E., NNES IV-22B (McGraw-Hill, New York, 1954).

${ }^{30}$ Neary, G. J., Munson, R. J., and Mole, R. M., "Chronic Radiation Hazards" "(Pergamon Press, London, 1957).

${ }^{31}$ Curtis, H. J., in "Medical Physics", 3, edit. by Glasser, O. (Yearbook Publishers, Chicago, in the press).

${ }^{32}$ Mole, R. H., Nature, 180, 456 (1957).

${ }^{3}$ Yockey, H. P., in Oak Ridge National Laboratory Report ORNL2806 (1959).

${ }^{34}$ Berlin, N. I., and Dimaggio, F. L., Armed Forces Special Weapons Project, Wash., Report AFswP-608 (1956).

${ }^{35}$ Failla, G., and McClement, Patricia, Amer. J. Roentgenol., 78, 946 (1957).

${ }^{36}$ Sacher, G. A., Grahn, D., and Gurian, Joan M., in Argonne National Laboratory Report ANL-5916.

${ }^{37}$ Noble, J. F., Doull, J., Hasegawa, A. T., and Landahl, H. D., USAF Radiation Laboratory Report 32 (1959).

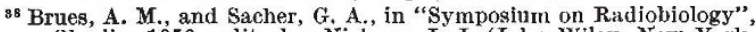
oberlin, 1950, edit. by Nickson, J. J. (John Wiley, New York, 1952).

s9 Kohn, H. I., and Guttman, P. H., Nature, 184, 735 (1959).

${ }^{40}$ (a) Storer, J. B., Rogers, B. S., Boone, I. U., and Harris, P. S., Radiat. Res., 8, 71 (1958). (b) Curtis, H. J., and Gebhard, Katharine, ibid., 9, 278 (1953). (c) Furth, J., Upton, A. C., and
Kimball, A. W., ibid., Supp. 1, 243 (1959). (d) Nowell, P. C., and Cole, L. J., ibid., 11, 545 (1959). (e) Vogel, jun., H. H., and Jordan, D. L., Argonne National Laboratory Report ANL-5916. ( $f$ ) Upton, A. C., personal communication (to be published).

${ }^{41}$ Lea, D. E., "Actions of Radiations on Living Cells" (Cambridge University Press, 1946 and 1955).

${ }^{42}$ Vogel, jun., H. II., Argonne National Laboratory Report (in the press).

${ }^{43}$ Russell, W. L., Russell, Liane B., and Kelley, Elizabeth M., Science, 128, 1546 (i958)

4 Hursh, J. B., University of Rochester Report UR-506 (1957).

45 Evans, T. C., Radiology, 50, 811 (1948).

${ }^{6}$ Mole, R. H., Brit. J. Radiol., 32, 497 (1959). Cole, L. J., Nowell, P. C., and Arnold, J. S., Radiat. Res., 12, 173 (1960)

4" Lansing, A. I., J. Geront., 2, 228 (1947). Sonneborn, T. M., and Schneller, Myrtle, in "Proc. Gatlinburg Conf. Aging, 1957" (American Institute of Biological Sciences, Wash., to be published).

18 Edington, C. W., and Kandolph, M. L., Genetics, 43, 715 (1958).

10 Burnet, Sir Macfarlane, Brit. Med. J., ii, 645, 720 (1959).

so Burnct, Sir Macfarlane, "The Clonal Selection Theory of Acquired Immunity" (Cambridge University Press, 1959).

${ }^{s 1}$ Perks, W., J. Inst. Actuaries, 63, 12 (1932).

¿2 Quastler, H., “Ann. Rev. Nuclear Sci,”, 8, 387 (1958).

${ }^{63}$ Linschitz, H., in "Information Theory in Radiobiology", edit. by Quastler, H. (University of Illinois Press, Urbana, 1953).

54 Szilard, L., Nature, 184, 957 (1959).

5. Mendell, J. S., Oak Ridge National Laboratory Report ORNI-2533 (1958).

${ }^{68}$ Carlson, L. D., and Jackson, 13. M., Radiat. Res., 11, 509 (1959).

${ }^{57}$ Boche, R. D., in "Biological Fffects of External Radiation", edit by Blair, H. A., NNES VI-2 (MeGraw-Hill, New York, 1954).

sв Jones, H. B., Kaiser Fdn. Med. Bull., 4, 329 (1956).

${ }^{5}$ Lewis, E. B., Science, 125, 965 (1957). Court Brown, W. M., and Doll, R., in "Peacefu) Uses of Atomic Energy", 23 (United Nations, Geneva, 1958).

\title{
COMBUSTION AND PROPULSION
}

\section{HIGH MACH NUMBER AIR-BREATHING ENGINES}

$\mathrm{T}$ HE Advisory Group for Aeronautical Research and Development, familiarly known as AGARD to aeronautical scientists, is both the concept and the achievement of one man-eminent mathematician in the field of aeronautics for so long as to have become almost legendary. Theodore von Kármán saw the need immediately after the Second World War for some organization in Europe to recreate the aeronautical strength of those countries which had been prevented from working in the field, and had, indeed, been largely isolated from the very rapid development which had then taken place during the War.

It was clear that such an organization had to be under the general sponsorship of NATO; but the orthodox solution of an international body composed largely of officials and the military was not what von Kármán desired. Instead, he created what was for all practical purposes an international learned society, having the great advantage of being supported financially by a military treaty organization; although depending upon that support, von Kármán has always insisted on an administrative autonomy for AGARD, which has been largely responsible for its scientific independence and quality. Ho became its first chairman and has been unanimously re-elected to that post each year since.

AGARD held its fourth Combustion and Propulsion Colloquium, on "High Mach Number Airbreathing Engines", in Milan during April 4-8. Appropriately enough, the sessions were held in the Museum of Science and Tochnology erected to the memory of that illustrious and most famous citizen of Milan, Leonardo da Vinci ; so, surrounded by copies of diagrams from the master's sketch book and working models which showed he had, in any event, considered these problems ages ago, some three hundred and seventy scientists from most of the free European nations, the United States and Canada met for discussion. The team from the United States was extremely strong, and, as would be expected, made the largest and most vigorous scientific contributions, undoubtedly due, in part, to a very liberal interpretation of the security regulations by the American authorities.

The choice of the subject of high-speed, airbreathing engines, in the current fashion for space science, is possibly unusual. In the United States it appoars that official support for research into airbreathing engines has largely been terminated in favour of the extensive programmes of rocket research and development for space exploration. The gigantic air-supplying plants at the experimental establish. ments of the National Aeronautical and Space Agency and the U.S. Air Force which were originally built for gas turbine and ram-jet research have been almost entirely converted into test facilities for rocket research.

It became clear in the opening speeches of the colloquium that the above state of affairs was causing a good deal of concern in many scientific quarters in the United States. Indeed, the first four papers, all by Americans, were in the nature of both an apologia and an explanation for the choice of subject. Von Kármán, in his opening address as chairman, pointed out that although one of the first to advocate the missile and rocket applications to flight, he now felt that the very enthusiasm with which this challenging branch of science and technology had been taken up was causing an unbalanced programme of research 
and development. He said that it was not unreasonable to expect that, considering the limitations of human physiology, the urge for yet faster manned flight through the atmosphere would be more attractive and more useful than a few space explorations using ion or plasma engines utilizing nuclear power and lasting for several years.

At present, military manned aircraft fly at twice the speed of sound, and engineers are considering seriously the building of civil airliners which will cruise at least as fast. Well-behaved missiles cruise at Mach 10-20, and von Kármán felt that it was in the intermediate range of Mach 3-10 that useful developments could take place, but only if really serious scientific effort was applied to the many research problems involved.

On the military side, von Kármán said that he strongly suspected that future study of the problems would show that the role of manned aircraft was, as yet, far from being terminated and that the development of vertical take-off techniques would broaden even further the usefulness of very high performance aircraft using air-breathing engines.

In the second paper of the opening session, Admiral J. T. Hayward, the only military speaker, who is deputy chief of development, U.S. Department of Navy, supported the same view, pointing out "the advantages of using an oxidizer, which is there for the asking". He went on to describe certain broad fields of military applications of very high speed, airbreathing engines both in missiles and manned aircraft.

Both the first two speakers said that developments of the ram-jet engine appeared to be the likely solution at speeds between Mach 5 and 8, although the disadvantage of this type of engine in having no static thrust and hence having to depend upon some other form of propulsion for take-off was stressed by Admiral Hayward.

The rest of the programme did indeed concentrate upon the problems of ram jets, apart from one session devoted to turbo-machinery. Before this, however, there were two more introductory papers by Prof. A. Ferri, of Brooklyn Polytechnic, and by M. A. Zipkin and L. M. Nucei, of the General Electric Co., which were devoted to somewhat superficial parametric studies of the different applications of ram jets in both the manned and missile fields, which the authors thought would be important in the future.

Ferri pointed out that in certain applications an air-breathing machine is the only practical solution, while in others it is an alternative to the rocket. In the former category he placed transportation and tactical warfare and in the latter a number of missile applications.

In the case of transportation, Ferri said that increase of flight speed not only decreased transit time but it also increased the range of an aeroplane. He pointed out that a great many of the major cities of the world were about 5,000 miles apart, and an aeroplane with such a range would be commercially attractive. It could only be attained economically by flying at Mach numbers of 4-8 rather than 2 or 3 and would use ram-jet engines for cruise, and turbojet engines designed essentially for the accelerating phases.

$\mathrm{He}$ also described a system for placing a large payload into orbit; and then landing without damage. Such a vehicle would take off like an aeroplane using turbo-jet engines, accelerate gently to orbital speed under full control in time and position, using ram-jet engines with subsonic burning in the lower range of supersonic flight, but at hypersonic speeds the internal flow in the combustion chambers would be supersonic. Such a vehicle would weigh between 130,000 and 400,000 lb. at take-off and could place a payload of $10,000 \mathrm{lb}$. in orbit. Although requiring much basic research, Prof. Ferri felt such a vehicle would be far more efficient and far more useful than present solutions based entirely on very large rocket motors. He made a strong plea for a small but continuing research effort in the airbreathing engine field, pointing out that if not, the existing technological ability and scientific background accumulated in many years of work would be lost. He considered that a resumption of such work at a much later date would necessitate a far larger effort.

Zipkin and Nucci elaborated the theme of composite, air-breathing systems, reviewing the performance characteristics of present engines and the trends of improvements in future engines. Performance figures from this work were then used to study a number of applications.

The first was the use of an accelerating air-breathing first stage for launching satellites or sounding rockets. In these systems, the launching vehicle might be a supersonic fighter or other very high performance aeroplane which would release the final rocket stage at $60,000-80,000 \mathrm{ft}$. Such systems, on the authors' assumptions, showed gains of as much as 60 per cent in the ratio of orbital weight to take-off weight, as compared with two-stage rocket systems. It is worth noting that the launching structure weight is much higher in the former case, but since the launcher is not expendable, a net saving in cost should ensue if the number of launchings was high enough, together with a much greater flexibility of operation since satellite launching programmes could be undertaken from conventional airports. This, in itself, would also lead to a much greater choice of initial orbit inclinations.

The second system studied by Zipkin and Nucci was a composite supersonic transport, capable of transporting sixty passengers 3,500 miles at Mach 4 . Again, there were two stages and, as would be expected, the staged system was about two-thirds the weight of a single aeroplane, and less fuel was consumed by the former. This is not a convincing example, since a similar, if less strong, argument for staging can be applied to present subsonic transports, again with similar performance gains. In fact, such systems have been tried (for example, the Mayo composite aircraft), but have never been attractive to operators because of the much greater capital and maintenance costs, and of the difficulties of operation.

The main part of the colloquium dealt with the research necessary to develop ram jets up to hypersonic speeds between Mach 4 and 10. Essentially, a ram-jet engine consists of three components, namely, an air intake, a combustion zone and an exit nozzle. Air must be efficiently decelerated and compressed in the intake, then energy added by burning fuel in the air stream and finally the heated gas is accelerated and expanded to ambient pressure. At speeds of around Mach 3-4 such processes are reasonably straightforward, although, since most of the work takes place in the intake and exit nozzles, ram jets are extremely sensitive to exact matching of the three components, otherwise useful thrust (that is, thrust greater than drag) will not result. 
As speeds increase into the hypersonic regions, the difficulties increase greatly. In the first place, the stagnation temperatures at hypersonic speeds are very high (around $5,000^{\circ} \mathrm{R}$ at Mach 8 ), even though the ambient temperature of the air is that associated with the stratosphere. There appears to be, indeed, a propulsion 'corridor' to high performance which relates altitude and Mach number, and bordered on one hand by maximum stagnation temperature and maximum internal working pressure, and on the other by minimum pressure for combustion. While much can be done to alleviate the temperature problem by radiation cooling and by using the evaporation of the fuel, there remain extremely serious material problems which were discussed at a later session of the colloquium. It is of interest to note that there is the possibility of compressing the air externally under a hypersonic wing, and spraying fuel into the decelerated flow. In other words, the ram jet can possibly be turned inside out with a very great gain of radiation cooling.

The design of an efficient air intake for one particular hypersonic speed is not difficult. However, in any practical ram jet the efficiency must remain high over the wide range of speeds and altitudes through which the engine accelerates to the cruise condition. This necessitates great variations in the shape and area of the intake. Ideally, a continuous variation is required, but, in general, the weight involved forces compromise solutions.

In all current ram jets and turbo jets, the air is decelerated in the intake to subsonic speed; but in the case of the hypersonic ram jet the problem of the intake would be eased if only partial deceleration took place. This, however, throws a greater burden on the design of the combustion chamber since little is known about stable combustion in a supersonic air stream.

It is of interest to note that, at hypersonic speeds, kinetic energy recovery is a more convenient way of expressing the adiabatic efficiency of an intake rather than the pressure recovery ratio used at lower speeds.

Finally, the exit nozzle has also to be designed to deal with the same wide range of Mach numbers and altitude as the intake, and consequently variable geometry is once more necessary. There are, however, two additional difficulties : first, the extremely high gas temperatures severely limit mechanical solutions. The second difficulty is of a more fundamental nature. The transit time of the air through the engine is of a similar order to the recombination times of the dissociated products of combustion. At present there is a great deal of uncertainty as to the amount of recombination which takes place before the hot gases leave the nozzle, the difference between the thrust of the equilibrium flow and the 'frozen' flow thrust of complete dissociation being enough to rule out the latter as leading to a useful engine with a thrust greater than its drag.

It will be seen, therefore, that the development of air-breathing engines for hypersonic propulsion throws open new fields of research, both in gasdynamics and thermodynamics, which are likely to be very fruitful. The authors of the papers which followed had accepted this challenge, and presented a great deal of new and valuable work, none the less interesting because of its controversial nature. Indeed, the discussions, which at conferences of this nature are not usually very stimulating, were on occasion extremely brisk.
Both J. A. Drake and C. L. Dugger, of Johns Hopkins University, presented papers dealing with the ram jet as an entity. The former especially stressed the need for additional research effort in the determination of exhaust nozzle recombination rates. Dugger's paper consisted of a theoretical comparison of hypersonic ram jets with subsonic and supersonic combustion. His calculations assumed that stable combustion can be achieved in supersonic flow, an assumption which is open to some doubt on present evidence.

On the basis of equilibrium flow, Dugger predicts that a significantly better performance can be achieved with supersonic combustion than with subsonic at speeds in the Mach 8-10 range ; in addition, lower combustion chamber pressures and temperatures may ease the design problems. However, making further assumptions about the degree of recombination, he showed that when kerosene is the fuel, the supersonic combustion chamber must be operated at pressures almost the same as in the subsonic case in order to achieve reasonable performance.

The next session was devoted to two papers by J. F. Connors and L. J. Oberry, of the National Aeronautical and Space Agency, and G. H. McLafferty, of United Aircraft, describing basic studies on air intakes. Intakes with both internal and external compression were examined and the great importance of variable geometry in both cases was emphasized. It was also shown that difficult viscous effects will be present which will necessitate complicated boundary layer control devices for maximum performance.

In logical order, the following sessions were devoted to combustion problems and to investigations of the reactions taking place in exit nozzles.

H. Behrens and F. Roessler, of the historic rocket establishment at Saint Louis, which is now under combined French and German direction, described some elegant experiments with supersonic diffusion flames, obtained by passing a supersonic jet of the hot, but not fully oxidized, gases from a solid rocket into air or oxygen. It was shown that with propellants of high heat of explosion stable flames were produced with no ignition delay at the first shock of the jet, while with propellants of low heats of explosion, ignition occurred with a delay, behind the first shock. The latter flames became unstable as the heat of explosion of the rocket propellant became less, although a greater stability was achieved with pure oxygen than with air.

P. P. Wegener, of the Jet Propulsion Laboratory, California Institute of Technology, chose the simpler and better-known system of a reacting mixture of nitrogen tetroxide and dioxide carried through a supersonic nozzle with a stream of nitrogen. By choice of conditions flows which were either in chemical equilibrium or in states between equilibrium and 'frozen' flow could be obtained, the recombination co-efficients being determined from optical absorption or static pressure measurements. As was pointed out in the discussion by K. N. C. Bray, of the University of Southampton, these experiments gave excellent agreement with his own theoretical predictions about non-equilibrium flows through supersonic nozzles and shock-waves.

E. A. Lezberg and R. B. Lancashire, of the National Aeronautical and Space Agency Lewis Research Centre at Cleveland, Ohio, described similar nozzle 
investigations on a much larger scale using hydrogen/ air mixtures. In this case the rate of recombination of the dissociated products of combustion was derived indirectly from performance calculations based upon static pressure and temperature measurements. The results indicated that although deviations from equilibrium flow occur downstream of the nozzle throat, recombination may be occurring throughout the length of the nozzle.

A further paper in the combustion series was a distinguished contribution by A. K. Oppenheim and P. A. Stern, of the University of California, in which the applicability of detonation wave studies to hypersonic combustion was investigated. The authors pointed out that the very stability of a detonation wave makes possible very precise observation and measurement, which could lead to an understanding of many of the problems in a ram jet, such as, for example, the propagation of non-equilibrium disturbances through compressible and reactive gaseous mixtures.

Detonation waves discovered by the early classical work of Berthelot Le Chatelier and others were studied from a thermodynamic point of view by D. L. Chapman and E. Jouget around the turn of the century. These workers demonstrated that detonation waves are complicated systems of shock waves followed immediately by deflagration; and later work, by means of more sophisticated instrumentation, has enabled the structure of the wavefront to be examined in much greater detail. It is clear that the team at the University of California has made great advances in this fascinating field of thermodynamics.

Not the least useful part of the paper by Oppenheim and Stern was the historical review of earlier work on detonations and explosions, together with more than two hundred references to other published work. The paper may well, therefore, become a standard reference in this field.

Following these papers on thermodynamics was the only paper on gas-turbine engines, somewhat out of context, since the speed-range considered was only up to Mach 3, and somewhat unfortunate in that it was one of the only two British papers. Nevertheless, it did reflect the emphasis in Britain of the continued importance of the lower Mach number range. Prof. J. H. Horlock, of the University of Liverpool, presented a very interesting paper on the research in turbomachinery which was still essential for the development of gas turbines capable of propelling aircraft at speeds up to Mach 3. $\mathrm{He}$ reviewed the current work on component efficiency, stability of compressors, blade cooling and maldistribution in the intake and compressor, all fields in which he considered there remained many problems requiring fundamental research.

Curiously, no mention was made of combustion problems which are certainly not well understood at Mach 3, nor was there any reference to the great difficulty of dealing with the noise caused by such engines, which may be a dominating factor in the choice of efflux velocity and relative mass flow.

Again, this paper contained a very useful list of nearly sixty references to the published literature.

Finally, the last session was devoted to the materials problems raised by the very high temperatures of hypersonic air-breathing engines. Papers were presented by A. J. Murphy and A. J. Kennedy, of the College of Aeronautics, Cranfield, and by P. Duwez, which were remarkable for their similarity of thought -indeed, each contained an identical diagram relating activation energies for creep, stress rupture and self-diffusion with melting temperature. Working on these lines, but also grading on a basis of low density and high elastic modulus, the advantages of tungsten, molybdenum, chromium and beryllium as refractory materials were stated. Duwez pointed out that since ram jets were constructed mainly from sheet, metals were more attractive than cermets or ceramics; but Murphy and Kennedy stressed the surface reactivity of such metals and the need for research in surface protective methods. Both papers also referred to the use of graphite, with its very high sublimation temperature and its unusual property of increasing tensile strength with temperature up to about $2,500^{\circ} \mathrm{C}$.

Duwez, however, considered that materials research would not provide the entire answer to these hightemperature problems, and that porous wall cooling and ablation would be the ultimate solution for very high combustion temperatures. In the ensuing discussion, it was generally felt that the ultimate limit was likely to be an economic one.

So came to an end an extremely useful and fruitful colloquium, which provided an excellent forum for vigorous discussions in a relatively new field of applied science. As is general with AGARD meetings, the contribution of the American workers was both massive and excellent. Unusual, however, was the rather small contribution from Great Britain, the representatives of which were, in general, in the position of assimilating, rather than contributing, new information.
W. CAWOOD

\section{THE PLANT PATHOLOGY LABORATORY, HARPENDEN}

\section{BY W. C. MOORE, C.B.E.}

$\mathrm{T}$ HE Minister of Agriculture, Fisheries and Food, the Right Hon. John Hare, formally opened the new buildings of the Plant Pathology Laboratory at Hatching Green, Harpenden, on May 13, in the presence of more than $a$ hundred distinguished guests and a staff of nearly sixty. The Minister recalled that the Laboratory, familiarly known for years as "Path. Lab.", was one of the oldest scientific sections of the Ministry. It was founded in 1918 at the Royal Botanic Gardens, Kow, and three years later was transferred to a converted private house in Harpenden. During the next twenty years it had consolidated its position as a scientific liaison centre and a source of advice on all aspects of plant diseases and pests. The big development of the Laboratory had come in the past two decades along with advances in the study of crop protection. The Second World War had again focused attention on maximum food production, and with the need to cut down losses from diseases and pests the Laboratory became an impor- 